a rarefied condition of the air in the tympanum and a retraction of the membrana tympani.

The pneumatic otoscope may be used by the physi. cian sufficiently to prevent any adhesion of the membrana tympani to the posterior wall of the middle ear and to insure a normal movement to the ossicles. But in this particular variety of inflammation massage of the membrana tympani by any method is not so important as in sclerosis of the middle ear.

\section{ISCHIORECTAL ABSCESS.}

REOTAL FISTULA IN ITS CAUSATION-REPORT OF A CASE WITH TWO LARGE PUS-POCKETS.

Read before the Mississippi Valley Medical Association, at Nashville, Tenn., Oct. 11-16, 1898.

BY WM. BRITT BURNS, M.D. DECKERVILLE, ARK.

I am aware that it is maintained that ischiorectal abscess is an etiologic factor in rectal fistula rather than the reverse; indeed, I am convinced that in the main it originates from an untreated or improperly treated abscess, an abscess that has been punctured instead of having been widely incised, but for $\mathrm{my}$ purpose it will be only necessary to affirm that in the case I desire to direct attention to, the abscess was set up or reignited, if you please, by a rectal fistula of two years' standing.

S. T., a colored woman, aged 40 years, called on me one Sunday afternoon about 4 P.M., to lance a boil. She gave a history of having had a similar trouble two years before, but she had drawn that to a head and it opened itself; it would get better and then worse again; this condition of affairs continued with never more than a small discharge coming away, until about six months previous to consulting me, when the discharge ceased and she thought she was well. On examination I was particularly struck with an excresence just to the right of the anus, not unlike a rudimentary pig-tail, and upon closer observation, could make out that this excresence was provided with a caliber. The diagnosis of fistula was plain I did not attempt to find the other end of the fistulous tract, because the swelling was so great and the parts were so intensely painful that I did not care to inflict unnecessary pain upon the poor sufferer. As I have stated, the swelling was great, the most prominent symptom in fact; there was such a swelling that the rectal and gluteal folds were obliterated, the rectum was pressed closely upon the left ischium and temporarily obliterated the ischiorectal fossa, the right labia majora suffering a similar infringement. The diagnosis of abscess was also plain.

I stated to the patient that I could give her relief temporarily by opening the abscess and emptying the cavity well, but she should have an operation done for removal of the fistula, if she would have a radical cure. I believe all will agree with me that this procedure is correct. But in this particular case I would have failed on the first proposition, as I will state a little further along. She would have none of it. After suffering the tortures of the condemned for so many hours, that were evidently days to her, on Mon. day evening she called me and consigned herself to my care and keeping. I gave her two compound cathartic pills to be taken at bed hour and instructed that she should not eat anything for breakfast, that she be given a thorough bath, and an enema of a half gallon of hot water and two tablespoonfuls of glycerin, and that I would operate at 10 A.M. the next day.
Promptly at the appointed hour, with the assistance of Dr. Waldron Abernathy, who administered the anesthetic, and three or four negresses, who took their turn in "falling out," a term used among the negroes of the South to designate any condition that renders a person hors de combat-from nausea to extreme syncope. Suffice it to say, I did the cutting, sponging, and most of the holding.

Putting a grooved director into the pipe stem, I cut down upon it with the edge of the knife into the ischiorectal fosse, cutting wide and deep. Then, after an enormous quantity of foul pus had poured out and a copious bichlorid solution had been played over the exposed surfaces, with scissors and sharp curette I extended the cavity back to the sacrum, outward to the ischial tuberosity, and forward to the upper extremity of the labia majora, removing all the bluish spongy-looking tissue that is found in an ischiorectal abscess-and I do not remember to have seen this condition in any other locality a tinge that it appears to me is given to these tissues by the gases from the rectal pouch coming through the fistulous opening. I have always allowed the extent of this smoky or stained tissue to govern the extent of my operation. I am in the habit of removing every vestige of this colored and rotten tissue in whatever direction. After extending the wound as mentioned before, I likewise, with finger and curette, went to an alarming depth, removing the bluish spongy tissue described above, and cutting down hillocks to fit the valleys, if you please, to a smooth surface. It may be well to state that there were no tributaries to the fistulous tract, which tract was obliterated entirely by scissors and curette, the end opening into the gut being closed with two ordinary interrupted catgut sutures. The wound being thoroughly cleansed was now to all intents and purposes ready for the dressing.

It occurred to me to make one more survey of the upper part of the cavity; I swept my finger into the apex of the wound-the wound described a pyramid, base downward--and, though all the bluish spongy tissue had been removed, I felt it give, and to my surprise, indeed, horror, a full pint of very foul discolored pus poured out and over my wound. I was in despair. I was afraid I was into the pelvic cavity. I had the misfortune to have been initiated into rectal surgery on a case of ischiorectal abscess that communicated freely with the pelvic cavity-a fatal one. If I was not into the pelvic cavity, I was, I feared, so close to it that infection of that cavity might prove a strong probability. After again curetting and washing out the wound with a hot bichlorid solution, I inspected closely and found there was yet a barrier to the pelvic cavity. I was relieved. The wound was then packed with iodoform gauze and covered with a large pledget of cotton and a $\mathrm{T}$ bandage was put on. The wound was similarly dressed every day for two weeks, then every other day for four weeks; after this the patient was discharged to care for the wound herself, which I was persuaded she would do admirably.

The cicatrix extends - at this date, after a full recovery of eight months-from a level with, and one inch to the right of, the tip of the coccyx to the middle of the right labia majora, a straight white line, presenting the appearance of having united by first intention, with a little puckering at a point between the ischial tuberosity and anal opening:

It will be noted that this extensive cutting operation-indeed I believe it is designated a capital ope- 
ration by Professor Matthews of Louisville-was done outside the sphinoter muscle. I have neglected to say that the sphincter was divulsed early in action, and it might be of interest to mention that a Matthews' speculum-that being the instrument usedwas broken in doing so, so strong was the sphincter muscle.

I shall not conjecture what would have been the outcome if I had left that second pint of pus in this patient a few hours longer.

\section{THE ARTHRITIC DIATHESIS.}

BY R. ALEXANDER BATE, A.B., M.D.

CHIFF OF THE MEDICAL CLINIC AND ASSISTANT TO THE CHAIR OF THE PRINCIPLES AND PRACTICE OF MEDICINE AND CLINICAL MEDICINE, HOSPITAL COLLEGE OF MEDICINE.
LOUISYILLE, KY.

The term "diathesis" is applied to an inherited predisposition to alterations of nutrition. Nutrition consists of the transformation of non-living molecules into living cells (assimilation) which undergo chemic changes with oxygen (reaction), producing waste material that in time is thrown off to make room for fresh cells (disassimilation). Nutrition is controlled by the nervous system, and is modified by age, sex, climate, food, geographic and geologic position, occupations, manners and customs, hygienic conditions, variations of light, heat, moisture and atmosphere (environment). Continuous subjection to any of these conditions modifying nutrition becomes apparent in the progeny of individuals; and this functional alteration of nutrition, causes a predisposition to pathologic conditions, or a pathologic condition itself, known as diathesis.

Bouchard defines "constitution" as including all that is concerned with the structure and framework of the body; while the word "temperament" includes everything that pertains to the individual characteristics and functional activity. Constitution and temperament are the gifts of heredity, and, either healthy or morbid, are transmitted from parent to progeny. Hence diathesis is morbid temperament.

Two diatheses are admitted: scrofula, or a predisposition to tuberculosis, and arthritism, or a predisposition to certain diseases characterized by retardation of the processes of nutrition. The latter is for our present consideration. The alterations in arthritism are purely functional, consequently there is no morbid anatomy. Since there are disturbances in which the retrograde changes produce a persistent increase in the products of disassimilation, such as uric and lactic acids; and since, in some instances, in spite of diet and exercise, these materials are formed, we must assume that in this diathesis there is an inability on the part of the cells to produce oxidation, even when the necessary articles are furnished.

The various manifestations of arthritism are those forms of arrested metamorphosis characterized by the presence or excess of organic acids. Some of the aoids are volatile, and are eliminated by the skin and lungs; some may remain in the blood or be stored in the tissues; some effect changes by increasing acidity, while others unite with bases and do not affect the relative reaction of the fluids. Consequently, we have the manifestations or symptoms of arthritism varying according to the stage at which metamorphosis is arrested and according to the character and consequent retention or channel of retention. Thus uric acid, the most prominent product of disassimilation, causes one class of diseases when it is in solution in the blood, and another totally different class when it is precipitated into the tissues.

The diseases generally conceded as dependent upon the arthritic diathesis are: acid dyscrasia, rickets, osteomalacia, obesity, lithiasis, embracing biliary, renal and pancreatic ; diabetes mellitus and insipidus; rheumatoid arthritis; articular and abarticular rheumatism; gout in all its phases; the constitutional insanities, anemia, eczema, neuralgia, migraine, arteriocapillary fibrosis; nasal, bronchial and cardiac asthma, hemorrhoids, biliousness, dyspepsia, paralysis, neurasthenia, hysteria, epilepsy, Reynaud's disease, albuminuria and Bright's disease.

In other words, as has been taught for some time, diseases may be divided into two classes, those having an external or foreign cause, as the microbic diseases, those having an internal or auto-cause, as those due to errors of metabolism. In the microbic type the oxygen is extracted from the blood by the foreign sources; in the metabolic type functional alteration or deficiency lessens oxygenation. Haig and Bouchard likewise strongly suggest that the action of drugs depends upon their power of increasing or diminish. ing this or that step of metabolism. Various forms of auto-intoxication are paralleled by the reaction from certain alkaloids.

In the first-mentioned manifestation of the arthritic diathesis-acid dyscrasia-there occurs during the process of oxidation a number of organic acids, such as uric, hippuric, oxaluric, oxalic, lactic and its derivatives, caprylic, caproic, valerianic, butyric, propionic, formic, acetic, stearic, oleic and palmitic, resulting from the incomplete oxidation of nitrogenous, saccharine, starchy and fatty substances, also from cholesterin, from the pancreatic juice and peptones and from glycocoll. Those formed in the alimentary canal, as lactic, its derivatives, etc., become absorbed and pass into the circulating liquids of the body and the tissues, where they undergo more or less trans. formation and elimination through the excretory organs. Carbonic and uric acids are usually combined with bases, and do not by their presence increase acidity in the tissues. Formic, acetic, butyric and several other volatile fatty acids are eliminated by the skin; butyric and cholalic also with the feces; renic, hippuric, oxaluric, carbonic, taurylic, damaluric, damalic, succinic and oxalic acids with the urine. Hydrochloric acid may exist in excess in the stomach, but more frequently the acidity is produced by the presence of some of the organic acids, as a consequence of fermentation induced by the presence of microphytic ferments.

In rachitis the primitive blood change is believed to be an excess of lactic acid, which holds the phosphate of calcium, etc., in solution, thus preventing the formation of infantile bone. Osteomalacia, on the other hand, occurs in the adult, and an excess of lactic acid dissolves the already formed bone. Obesity seems directly dependent upon oxidation. In addition to fat formed directly from food, there is a certain amount formed during retrograde metamorphosis, both of the nitrogenous and albuminoid constituents of the tissues. Obesity occurs in the anemic, on account of the diminished blood-current being insufficient to carry a normal amount of oxygen; likewise in the paralyzed, the nerve-cells being deficient. Oxidation of emulsified fat is more difficult than of the saponified, consequently arrest of the action of 